\title{
The Importance of Porins and $\beta$-Lactamase in Outer Membrane Vesicles on the Hydrolysis of $\beta$-Lactam Antibiotics
}

\author{
Si Won Kim ${ }^{1}$, Jung Seok Lee ${ }^{1}$, Seong Bin Park ${ }^{2}$, Ae Rin Lee ${ }^{1}$, Jae Wook Jung ${ }^{1}$, Jin Hong Chun ${ }^{1}$, \\ Jassy Mary S. Lazarte ${ }^{1}$, Jaesung Kim ${ }^{1}$, Jong-Su Seo ${ }^{3}$, Jong-Hwan Kim ${ }^{3}$, Jong-Wook Song ${ }^{3}$, \\ Min Woo Ha ${ }^{4}$, Kim D. Thompson ${ }^{5}$, Chang-Ro Lee ${ }^{6}{ }^{\circ}$, Myunghwan Jung ${ }^{7}$ and \\ Tae Sung Jung $1,8, *$ \\ 1 Laboratory of Aquatic Animal Diseases, Institute of Animal Medicine, College of Veterinary Medicine, \\ Gyeongsang National University, Jinju 52828, Korea; ksw0017@hanmail.net (S.W.K.); \\ leejs058@gmail.com (J.S.L.); gladofls@naver.com (A.R.L.); wjdwodnr0605@gmail.com (J.W.J.); \\ hilanamang@naver.com (J.H.C.); jassylazarte@yahoo.com (J.M.S.L.); afteru70@gmail.com (J.K.) \\ 2 Coastal Research \& Extension Center, Mississippi State University, Starkville, MS 39567, USA; \\ 9887035@hanmail.net \\ 3 Environmental Chemistry Research Center, Korea Institute of Toxicology Gyeongnam Department of \\ Environmental Toxicology and Chemistry, Jinju 52834, Korea; jsseo@kitox.re.kr (J.-S.S.); \\ jjong@kitox.re.kr (J.-H.K.); songjk@kitox.re.kr (J.-W.S.) \\ 4 College of Pharmacy, Jeju National University, 102, Jejudaehak-ro, Jeju-si, Jeju-do 63243, Korea; \\ beneminu_@naver.com \\ 5 Moredun Research Institute, Pentlands Science Park, Penicuik, Midlothian EH26 0PZ, UK; \\ kim.thompson@moredun.ac.uk \\ 6 Department of Biological Sciences, Myongji University, Yongin, Gyeonggido 449-728, Korea; crlee@mju.ac.kr \\ 7 Department of Microbiology, Research Institute of Life Sciences, College of Medicine, \\ Gyeongsang National University, Jinju 52727, Korea; mjung@gnu.ac.kr \\ 8 Centre for Marine Bioproducts Development, College of Medicine and Public Health, Flinders, University, \\ Bedford Park, Adelaide, SA 5042, Australia \\ * Correspondence: jungts@gnu.ac.kr; Tel.: +82-10-8545-9310; Fax: +82-55-762-6733
}

Received: 13 February 2020; Accepted: 16 April 2020; Published: 17 April 2020

\begin{abstract}
Gram-negative bacteria have an outer membrane inhibiting the entry of antibiotics. Porins, found within the outer membrane, are involved in regulating the permeability of $\beta$-lactam antibiotics. $\beta$-lactamases are enzymes that are able to inactivate the antibacterial properties of $\beta$-lactam antibiotics. Interestingly, porins and $\beta$-lactamase are found in outer membrane vesicles (OMVs) of $\beta$-lactam-resistant Escherichia coli and may be involved in the survival of susceptible strains of E. coli in the presence of antibiotics, through the hydrolysis of the $\beta$-lactam antibiotic. In this study, OMVs isolated from $\beta$-lactam-resistant E. coli and from mutants, lacking porin or $\beta$-lactamase, were evaluated to establish if the porins or $\beta$-lactamase in OMVs were involved in the degradation of $\beta$-lactam antibiotics. OMVs isolated from $E$. coli deficient in $\beta$-lactamase did not show any degradation ability against $\beta$-lactam antibiotics, while OMVs lacking OmpC or OmpF showed significantly lower levels of hydrolyzing activity than OMVs from parent $E$. coli. These data reveal an important role of OMVs in bacterial defense mechanisms demonstrating that the OmpC and OmpF proteins allow permeation of $\beta$-lactam antibiotics into the lumen of OMVs, and antibiotics that enter the OMVs can be degraded by $\beta$-lactamase.
\end{abstract}

Keywords: outer membrane vesicles (OMVs); $\beta$-lactamase; porin; $\beta$-lactam antibiotic; Escherichia coli; hydrolysis 


\section{Introduction}

Since the discovery of penicillin, antibiotics have been responsible for prolonging human life and advancing human medicine. However, antibiotic-resistant bacteria, also known as superbugs or multi-drug resistant (MDR) bacteria, have emerged due to the indiscriminate misuse of antibiotics [1,2]. O'Neill (2014) has estimated that by 2050, 10 million deaths will have occurred each year as a result of antibiotic resistance and this is estimated to cost up to 100 trillion USD [3]. In 2013, the U.S. Centers for Disease Control and Prevention predicted that at least 2 million antibiotic-resistant bacteria infections, resulting in a predicted 23,000 deaths, would cost around 20 billion USD in extra healthcare, leading to an economic loss of at least 35 billion USD in the U.S. each year [4]. In 2016, the UK government reported that 700,000 deaths occur worldwide each year as a result of antibiotic-resistant bacteria [5]. This problem is not confined to humans, but spreads across species, affecting agriculture, livestock, fisheries, food and the environment [6]. Antibiotic-resistant bacteria are now regarded as the biggest challenge facing public health and efforts to reduce MDR bacteria globally have increased substantially.

All Gram-negative bacteria secrete spherical membrane bilayer structures (10 to $250 \mathrm{~nm}$ ), referred to as outer membrane vesicles (OMVs), into the external environment during both in vitro growth and in vivo infection [7-10]. We now have a greater understanding of the composition, physicochemical properties and various roles of OMVs [8,10-17]. OMVs consist of outer membrane proteins, cytoplasmic proteins, periplasmic membrane proteins, phospholipids, lipopolysaccharides and genetic material $[8,12,13]$. More recent research has focused on the role of OMVs in protecting bacteria by directly participating in the bacteria's development of antibiotic resistance $[7,9,18-21]$. However, there are few in-depth studies examining the mechanisms OMVs use to protect bacteria against antibiotics. Although many studies have investigated the effects of $\beta$-lactam antibiotics on bacteria, showing inactivation of $\beta$-lactamase and mutation of porin-encoding genes [22-26], the interaction between $\beta$-lactamases and porins in OMVs and $\beta$-lactam antibiotics remains to be clarified. Our previous work showed that OMVs from $\beta$-lactam-resistant $E$. coli can help $\beta$-lactam-susceptible E. coli avoid the effects of $\beta$-lactam antibiotics through hydrolysis. In addition, porins (OmpC and OmpF) and $\beta$-lactamase (Blc1) were seen to be upregulated in OMVs of $\beta$-lactam-resistant E. coli compared to OMVs of $\beta$-lactam-susceptible E. coli [7]. Therefore, we hypothesize that the increased number of porin proteins are able to efficiently direct the $\beta$-lactam antibiotics into the OMVs lumen, and the increase in $\beta$-lactamase actively drives the degradation of $\beta$-lactam antibiotics, suggesting that antibiotic hydrolysis is commonly observed in OMVs from $\beta$-lactam-resistant E. coli $\left(\mathrm{RC}^{\circ} 5^{+}\right.$) (Figure 1). In the present study, we attempt to demonstrate $\beta$-lactam antibiotic hydrolysis by OMVs by making mutants containing ompC, ompF, or $b l c 1$ gene deletions and observing whether OMVs isolated from the mutants are able to consume $\beta$-lactam antibiotics within the bacterial environment and within a cell-free system.

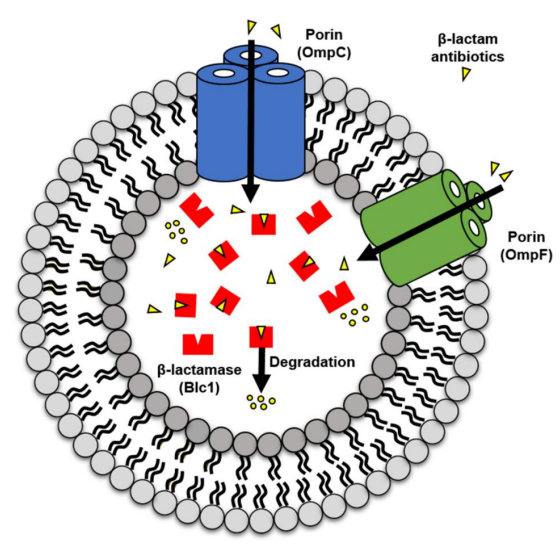

Figure 1. Predictive mechanism of $\beta$-lactam antibiotics degradation by outer membrane vesicles (OMVs) from $\beta$-lactam-resistant Escherichia coli $\left(\mathrm{RC}^{\circ} 5^{+}\right)$. OMVs take up $\beta$-lactam antibiotics into their lumen through porin channels (OmpC and $\mathrm{OmpF}$ ) and the $\beta$-lactamase (Blc1) in the lumen hydrolyzes the $\beta$-lactam antibiotics confined in the lumen of OMVs. 


\section{Results}

\subsection{Characterization of Mutant Strains}

To establish if Blc1, OmpC, or OmpF are involved in the OMVs' ability to degrade $\beta$-lactam antibiotics, mutants were produced from $\mathrm{RC} 85^{+}$by knocking out each of these genes. The successful deletion of $b l c 1, o m p C$, and $o m p F$ in mutant $R C 85^{+}$strains was confirmed by PCR amplification shown in Figure S1. Mutant strains grew well in LB medium, having a logarithmic phase growth similar to $\mathrm{RC}^{+} 5^{+}$(Figure 2). The deletion of blc1 and ompF had no distinguishable influence on growth rates, while the growth rate of $\triangle \mathrm{ompC} \mathrm{RC} 85^{+}$was slightly slower than that of $\mathrm{RC} 85^{+}$. When the growth on LB agar was observed, mutant strains formed smooth, slightly elevated, non-pigmented colonies, similar to those of $\mathrm{RC}^{+} 5^{+}$(data not shown). An antimicrobial sensitivity test was conducted with the mutant strains to determine whether changes in their antibiotic resistance occurred compared to $\mathrm{RC}^{+} 5^{+}$(Table 1). In the absence of the blc1 gene, the minimum inhibitory concentration (MIC) of all $\beta$-lactam antibiotics was reduced. In the case of $\triangle \mathrm{ompC}$, there was no difference in MIC levels relative to $\mathrm{RC} 5^{+}$, apart from the MIC for cefazolin, which was enhanced, whereas inactivation of the $o m p F$ gene conferred more resistance to cefoperazone, cefazolin, and cefalexin in the mutant compared with $\mathrm{RC} 85^{+}$.

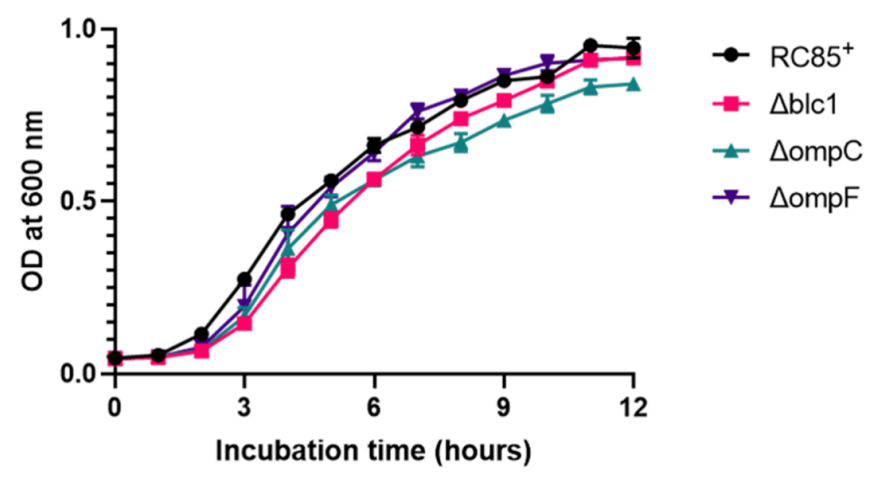

Figure 2. Growth curves of RC $85^{+}$and isogenic mutant strains of $\mathrm{RC} 85^{+}$( $\triangle \mathrm{blc1} 1, \Delta \mathrm{ompC}$, and $\Delta \mathrm{ompF}$ ). The $\mathrm{RC} 85^{+}$and mutant strains were cultured on LB medium, and the growth of each strain was investigated by measuring absorbance at $600 \mathrm{~nm}$. Data are presented as means and SEMs of three independent experiments.

Table 1. The MIC of $\beta$-lactam antibiotics and other class antibiotics against the multidrug-resistant Escherichia coli $\mathrm{RC} 5^{+}$and isogenic mutant strains of $\mathrm{RC}^{+} 5^{+}$.

\begin{tabular}{|c|c|c|c|c|c|}
\hline \multirow{2}{*}{ Class } & \multirow{2}{*}{ Antibiotics } & \multicolumn{4}{|c|}{$\operatorname{MIC}(\mu \mathrm{g} / \mathrm{mL})^{\mathrm{a}}$} \\
\hline & & $\mathrm{RC}^{+} 5^{+}$ & $\Delta$ blc1 & $\Delta o m p C$ & $\Delta o m p F$ \\
\hline \multirow{8}{*}{$\begin{array}{c}\beta \text {-lactam } \\
\text { antibiotics }\end{array}$} & Ampicillin & $>1024$ & 4 & $>1024$ & $>1024$ \\
\hline & Cefotaxime & $>1024$ & $<1 / 2$ & $>1024$ & $>1024$ \\
\hline & Cefoperazone & 1024 & $<1 / 2$ & 1024 & $>1024$ \\
\hline & Methicillin & $>1024$ & 256 & $>1024$ & $>1024$ \\
\hline & Amoxicillin & $>1024$ & 2 & $>1024$ & $>1024$ \\
\hline & Cefazolin & 1024 & 1 & $>1024$ & $>1024$ \\
\hline & Cefalexin & 512 & 8 & 512 & 1024 \\
\hline & Cloxacillin & $>1024$ & 128 & $>1024$ & $>1024$ \\
\hline \multirow{5}{*}{$\begin{array}{l}\text { Other class } \\
\text { antibiotics }\end{array}$} & Streptomycin & $>1024$ & $>1024$ & $>1024$ & $>1024$ \\
\hline & Kanamycin & $>1024$ & $>1024$ & $>1024$ & $>1024$ \\
\hline & Colistin & 4 & 4 & 4 & 4 \\
\hline & Amikacin & 8 & 8 & 8 & 8 \\
\hline & Nalidixic acid & $>1024$ & $>1024$ & $>1024$ & $>1024$ \\
\hline
\end{tabular}

${ }^{a}$ MIC indicates minimum inhibitory concentration. 


\subsection{Quantification of the Produced OMVs}

The OMVs from the mutants and $\mathrm{RC} 85^{+}$were isolated after incubation under the same culture conditions. Electron micrograph analysis exhibited the similarity of OMVs isolated from the mutants and $\mathrm{RC}^{+} 5^{+}$in size with the spherical structure (Figure S2). The average diameter of the OMVs from the $\Delta \mathrm{blc1}, \Delta \mathrm{ompC}$, and $\Delta \mathrm{ompF}$ cells was nearly identical, while $\mathrm{RC} 85^{+} \mathrm{OMVs}$ were slightly larger than these (Figure S3). Production of OMVs was evaluated with a BCA protein assay, with the production of OMVs slightly decreased in $\Delta$ blc1, but increased by 2.2- and 1.8-fold in $\triangle$ ompC and $\Delta \mathrm{ompF}$, respectively, relative to the level of OMVs produced by $\mathrm{RC} 85^{+}$(Figure 3).

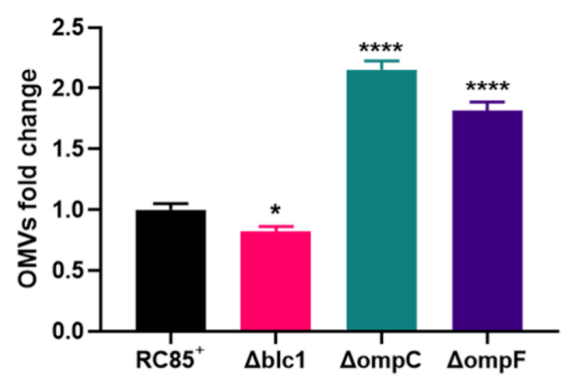

Figure 3. Production of OMVs isolated from $\mathrm{RC} 85^{+}$and isogenic mutant strains of $\mathrm{RC} 85^{+}(\Delta \mathrm{blc} 1, \Delta \mathrm{ompC}$, and $\triangle \mathrm{ompF}$ ). OMVs yields were averaged and normalized to $\mathrm{RC} 85^{+}$to adjust fold change. OMVs were purified and quantified using the BCA protein assay. Data are representative of three independent experiments in means \pm SEMs. ${ }^{*} p<0.05$, and ${ }^{* * * *} p<0.0001$.

\subsection{Comparison of $\beta$-Lactamase Activity}

Differences in $\beta$-lactamase activity between OMVs from $\mathrm{RC}^{+} 5^{+}$and the mutant strains were examined, based on a change in absorbance of $\mathrm{OD}_{490}$ over time (Figure 4a). Since nitrocefin can enter into bacteria through porins, the individual OMVs were destroyed by sonication to remove the variables for porins in OMVs. This liberates the $\beta$-lactamase present in the lumen of the OMVs. The absorbance obtained for mutant $\Delta$ blc1 was similar to the negative control, while mutants $\Delta$ ompC and $\Delta \mathrm{ompF}$ showed higher levels of absorbance than the positive control and they exhibited similar levels of $\beta$-lactamase activity to that of the $\mathrm{RC} 85^{+}$OMVs over the course of the experiment. The $\beta$-lactamase activity of the respective OMVs was expressed as milliunit per milligram $(\mathrm{mU} / \mathrm{mg})$ of OMV protein (Figure $4 \mathrm{~b}$ ). The $\beta$-lactamase activity of $\Delta \mathrm{ompC}$ and $\Delta \mathrm{ompF} O M V s$ was $72.4 \mathrm{mU} / \mathrm{mg}$ and $70.3 \mathrm{mU} / \mathrm{mg}$ respectively, nearly identical to those of $\mathrm{RC} 85^{+} \mathrm{OMVs}(64.4 \mathrm{mU} / \mathrm{mg})$. OMVs from $\Delta$ blc1 cells displayed the lowest $\beta$-lactamase activity of $2.7 \mathrm{mU} / \mathrm{mg}$.

(a)

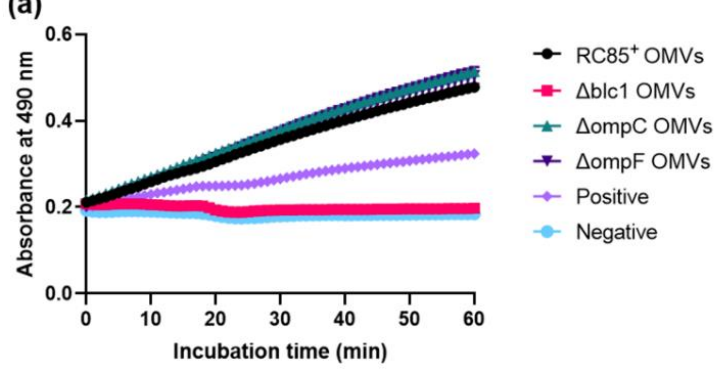

(b)

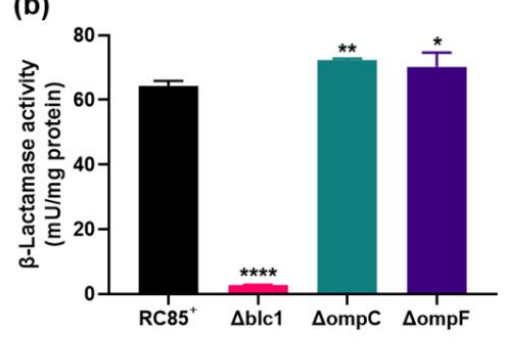

Figure 4. Investigation of the differences in $\beta$-lactamase activity between destroyed OMVs from $\mathrm{RC} 85^{+}$ and isogenic mutant strains of $\mathrm{RC} 85^{+}(\mathrm{blc} 1, \Delta \mathrm{ompC}$, and $\Delta \mathrm{ompF})$. (a) $\beta$-Lactamase activity profiles of samples were measured in a kinetic mode in $60 \mathrm{~min}$. Data are representative of three independent experiments in means \pm SEMs. (b) $\beta$-Lactamase units were normalized to milligrams of total OMV protein. The data are presented as means and SEMs of three independent experiments. ${ }^{*} p<0.05$, ** $p<0.01$, and ${ }^{* * * *} p<0.0001$. 


\subsection{Evaluation of the Protective Role of OMVs against $\beta$-Lactam Antibiotics}

To determine if the loss of porin or $\beta$-lactamase proteins from the OMVs influences the degradation of $\beta$-lactam antibiotics, we investigated the effect of OMVs from $\mathrm{RC} 85^{+}$and mutants $(\Delta \mathrm{blc1}, \Delta \mathrm{ompC}$, or $\Delta \mathrm{ompF}$ ) on the growth of $\beta$-lactam susceptible E. coli (RC85) cells in the presence of a growth-inhibitory dose of six $\beta$-lactam antibiotics (Figure 5). When $\mathrm{RC} 85^{+} \mathrm{OMVs}$ were mixed with the antibiotics corresponding to a growth inhibitory concentration for RC85, the cells grew at the same or slower rate than the positive control (RC85 cells in LB medium without antibiotics). RC85 treated with OMVs from the $\triangle \mathrm{ompC}$ mutant grew in all antibiotics tested, but their growth was slower than the samples containing RC $85^{+}$OMVs. Furthermore, RC 85 incubated with $\triangle \mathrm{ompF}$ OMVs grew after $24 \mathrm{~h}$ in cefoperazone and after $18 \mathrm{~h}$ in cefazolin, which was slower than that obtained with the $\triangle \mathrm{ompC} O M V \mathrm{~s}$, while no growth was detected in the presence of the other four antibiotics (ampicillin, cefotaxime, amoxicillin, and cefalexin) over the $36 \mathrm{~h}$ culture period. On the other hand, RC85 incubated with $\Delta \mathrm{blc1}$ OMVs did not show any growth when each of the six antibiotics was present. After the growth curve experiment (Figure 5), all samples were plated on nutrient agar with or without each of the antibiotics in the same concentration as was used in the growth curve experiment (data not shown). If the susceptible strains of E. coli (RC85) received antibiotic-resistant substances through OMVs during the experiment in Figure 5, it could grow on nutrient agar containing respective antibiotics. All samples that grew in the above experiment were grown in nutrient agar but not in nutrient agar with respective antibiotics. These results demonstrated that the survival rate of RC 85 was not due to transfer of $\beta$-lactam resistant materials to RC 85 by OMVs but was due to molecules owned by OMVs that protected the RC 85 from the antibiotic environment. The colonies grown in nutrient agar were identified as E. coli at the species level using the MALDI-Biotyper (Bruker Daltonics, Bremen, Germany, data not shown).

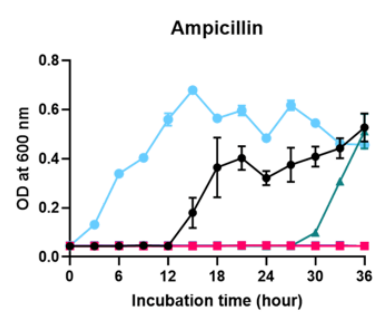

Amoxicillin
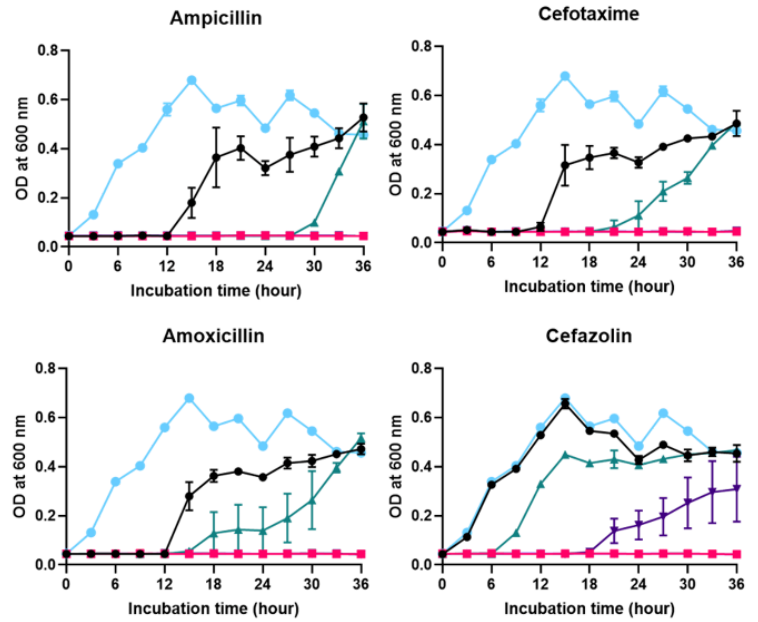

Cefazolin
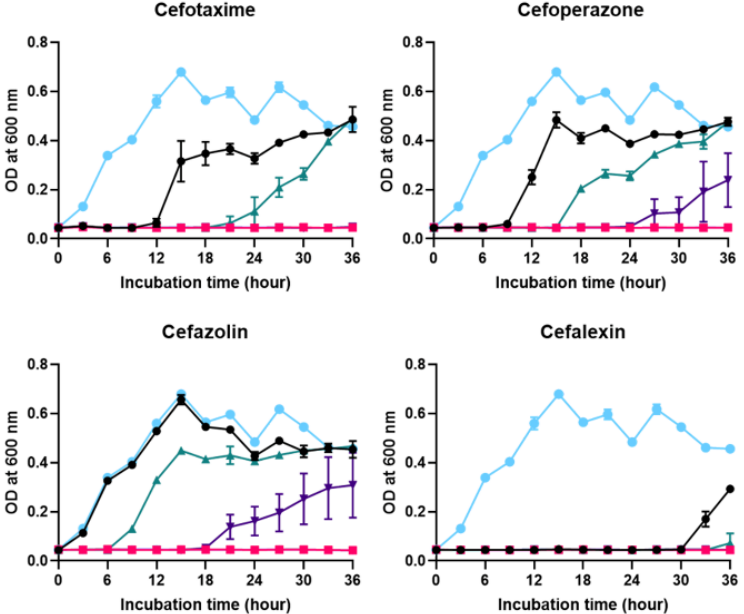

- Antibiotic + RC85 + RC85+ OMVs - Antibiotic + RC85+ $\mathrm{Bblc1}$ OMVs

- Antibiotic + RC85 + $\triangle$ ompC OMVs

- Antibiotic + RC85 + $\triangle \mathrm{ompF}$ OMVs

$\rightarrow$ Antibiotic + RC85

$\rightarrow \mathrm{LB}+\mathrm{RC} 85$

Figure 5. Growth of $\beta$-lactam-susceptible Escherichia coli (RC85) cells in antibiotic-induced growth inhibition environment to evaluate the antibiotic consumption role of intact $\mathrm{OMV}$ srom $\mathrm{RC}^{+} 5^{+}$and isogenic mutant strains. The growth-inhibiting concentrations of $\beta$-lactam antibiotics were: ampicillin, $30 \mu \mathrm{g} / \mathrm{mL}$; cefotaxime, $1.25 \mu \mathrm{g} / \mathrm{mL}$; cefoperazone, $4 \mu \mathrm{g} / \mathrm{mL}$; amoxicillin, $12 \mu \mathrm{g} / \mathrm{mL}$; cefazolin, $8 \mu \mathrm{g} / \mathrm{mL}$; cefalexin, $16 \mu \mathrm{g} / \mathrm{mL}$. The data are presented as means and SEMs of three independent experiments.

\subsection{Hydrolysis of $\beta$-Lactam Antibiotics by OMVs}

Concentrations of $\beta$-lactam antibiotics were measured at specific time points in a cell-free system to determine whether $\beta$-lactam antibiotics could be hydrolyzed by the OMVs (Figure 6). Compared with the positive control, containing antibiotics without OMVs ( $0 \%$ hydrolysis), there were significant differences observed between OMVs from $\mathrm{RC} 85^{+}, \Delta \mathrm{blc1}, \triangle \mathrm{ompC}$, and $\triangle \mathrm{ompF}$ in their ability to degrade the different $\beta$-lactam antibiotics tested. With all six $\beta$-lactam antibiotics examined, $\mathrm{RC} 85^{+} \mathrm{OMVs}$ showed the highest hydrolytic activity, followed by $\triangle \mathrm{ompC}$ then $\triangle \mathrm{ompF}$ OMVs, while no change 
in antibiotic concentration was noted with $\Delta$ blc1 OMVs. These results imply that $\beta$-lactamase is the most important factor in the degradation of $\beta$-lactam antibiotics by $\mathrm{RC} 85^{+} \mathrm{OMVs}$, alongside porin, specifically OmpF, which showed higher permeability to all six $\beta$-lactam antibiotics tested when compared to OmpC.

(a)

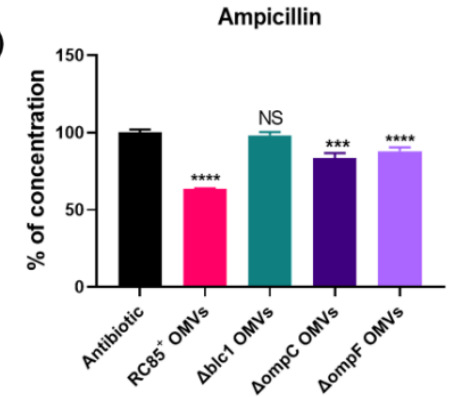

(d)

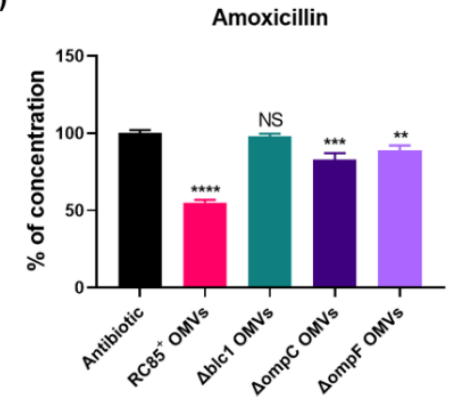

(b)

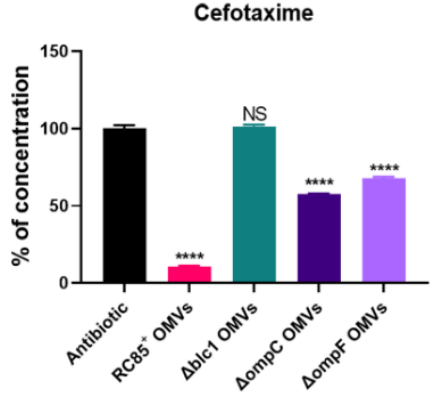

(e)

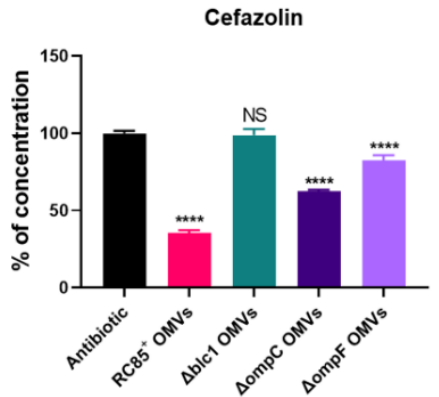

(c)

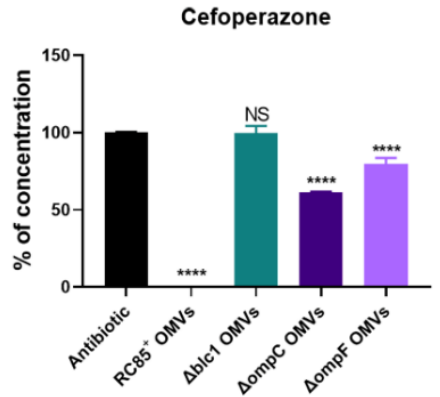

(f)

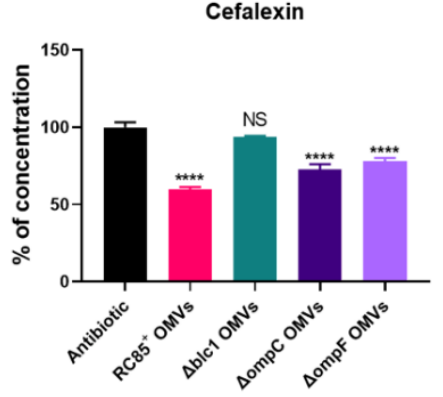

Figure 6. Evaluation of the concentration of $\beta$-lactam antibiotics incubated with $5 \mu \mathrm{g} / \mathrm{mL}$ of intact OMVs from $\mathrm{RC} 85^{+}$and isogenic mutant strains of $\mathrm{RC} 85^{+}(\Delta \mathrm{blc} 1, \Delta \mathrm{ompC}$, and $\Delta \mathrm{ompF})$. The initial concentrations and certain time points for measurement were as follows: ampicillin, $30 \mu \mathrm{g} / \mathrm{mL}, 5 \mathrm{~h}(\mathbf{a})$; cefotaxime, $1.25 \mu \mathrm{g} / \mathrm{mL}, 4 \mathrm{~h}$ (b); cefoperazone, $4 \mu \mathrm{g} / \mathrm{mL}, 3 \mathrm{~h}$ (c); amoxicillin, $12 \mu \mathrm{g} / \mathrm{mL}, 5 \mathrm{~h}$ (d); cefazolin, $8 \mu \mathrm{g} / \mathrm{mL}, 1 \mathrm{~h}(\mathbf{e})$; cefalexin, $16 \mu \mathrm{g} / \mathrm{mL}, 11 \mathrm{~h}$ (f). Respective antibiotics without OMVs were averaged and normalized as $100 \%$, and the corresponding concentration of antibiotics with OMVs were calculated. The data are presented as means and SEMs of three independent experiments. The abbreviation 'ns' means not significant. ${ }^{* *} p<0.01,{ }^{* * *} p<0.001$ and ${ }^{* * *} p<0.0001$.

\section{Discussion}

We previously showed that porin proteins and $\beta$-lactamase enzyme are more abundant in OMVs isolated from $\beta$-lactam-resistant $E$. coli than from $\beta$-lactam-susceptible E.coli, and only OMVs from $\beta$-lactam-resistant E. coli were found to degrade $\beta$-lactam antibiotics [7]. Therefore, here we were interested in establishing whether the loss of porin or $\beta$-lactamase could directly influence the hydrolysis efficiency of OMVs, especially since the mechanism by which OMVs degrade $\beta$-lactam antibiotics is unknown. The aim of the present study was to establish what significance $\beta$-lactam antibiotic resistance-associated proteins, such as $\beta$-lactamase and porin, had on the production and activity of $\beta$-lactamase, and on the ability of OMVs from E. coli to degrade $\beta$-lactam antibiotics. Our results suggest that it is not the loss of $\beta$-lactamase but the loss of porin from the outer membrane of the OMV that influences the yield of OMVs obtained. The loss of porin does not affect the $\beta$-lactamase activity of OMVs but the loss of $\beta$-lactamase dramatically eliminated $\beta$-lactamase activity by the OMVs. Thus, the presence of $\beta$-lactamase and porin in the OMVs plays a significant role in the direct hydrolysis of $\beta$-lactam antibiotics.

Many studies have demonstrated that OMVs serve as a defense by the bacterium against antimicrobial peptides and antibiotics. For instance, OMVs from $\beta$-lactam-resistant $E$. coli plays an important role in the growth of susceptible bacteria by degrading $\beta$-lactam antibiotics before they can affect the bacteria [7]. OMVs containing $\beta$-lactamase enzymes inactivate some $\beta$-lactam 
antibiotics $[7,19,20,27]$ or sequester some antibiotics [9], both leading to the protection of bacteria against corresponding antibiotics. OMVs can act as a vehicle for disseminating genetic material, including antibiotic resistance genes to susceptible bacteria, thereby contributing to the production of antibiotic-resistant bacteria $[18,28,29]$. These bacteria can protect susceptible bacteria by serving as decoys or acting as a physical shield, which helps them to evade the influence of some antibiotics [7,30-32]. Substances involved in antibiotic resistance are relatively safe from dilution and degradation because they are packed safely inside the OMVs [33]. Our results show that OMVs from $\mathrm{RC} 85^{+}$directly degrade $\beta$-lactam antibiotics to protect sensitive strains from antibiotic environments (Figures 5 and 6 ).

Several studies have demonstrated that the loss of porins from the bacterial outer membrane can impact the production of OMVs. For example, Mcbroom et al. (2006) indicated that relative OMV production from an E.coli ompC mutant was significantly enhanced by almost 10 -fold compared to the wild-type E.coli [34]. A deletion in $\operatorname{omp} A$, encoding an outer membrane $\beta$-barrel protein with a periplasmic peptidoglycan-interaction domain resulted in a 26 -fold hypervesiculation in $E$. coli mutant [35]. Valeru et al. (2014) showed a 3-fold increase in the level of production of OMVs by an OmpA mutant of Vibrio cholerae compared to the wild-type [36]. In line with these findings, our results showed that a lack of porins enhances the release of OMVs (Figure 3). The E. coli cells lacking porin proteins in their outer membrane (OmpC and OmpF) showed instability, with increased OMVs production due to a structural deficiency of the outer membrane [37]. Therefore, we speculate that a loss of porins alters the composition of the envelope membrane, which in turn affects membrane integrity, leading to enhanced secretion of OMVs.

$\beta$-lactam antibiotics are widely used antibiotics that are highly effective in combating bacterial infections [38]. These include penicillin derivatives, cephalosporins, monobactams, and carbapenems, and work by inhibiting cell wall biosynthesis, causing bactericidal effects for the bacteria. E. coli has developed four major mechanisms to resist the inhibitory effect of $\beta$-lactam antibiotics: inactivation of the antibiotics by enzymes, alteration of the active site of PBPs (penicillin-binding proteins), decreased permeation of the antibiotics and increased efflux of the antibiotics $[39,40]$. $\beta$-lactamases in the periplasmic space break the structure of the $\beta$-lactam ring, making the molecule's antibacterial properties inactive so that antibiotics are unable to bind to PBPs [41]. Porin proteins produce transmembrane diffusion channels in the outer membrane that enable the diffusion of small hydrophilic molecules (e.g., sugars, amino acids, and vitamins) and $\beta$-lactam antibiotics to penetrate into the periplasmic space [42-44].

An observed decreased in the resistance of the $\beta$-lactamase mutants to $\beta$-lactam antibiotics compared with the wild-type was due to reduced $\beta$-lactamase activity $[45,46]$. Previous studies revealed that $\mathrm{OmpC}$ seems to be related to the transport of some $\beta$-lactam antibiotics [47-50]. Choi and Lee (2019) demonstrated that the OmpF-defective E. coli mutants showed increased resistance to several $\beta$-lactam antibiotics, such as ampicillin, cefalotin, cefoxitin, ceftazidime, aztreonam, and imipenem [47]. The absence of OmpF classical porin resulted in a significant increase in $\beta$-lactam resistance, including ampicillin and cefoxitin [51]. Our findings corroborate previous reports that the MIC against several $\beta$-lactam antibiotics was decreased or increased in single isogenic $\beta$-lactamase or porin mutants, respectively (Table 1). Based on the available data, we speculate that the change seen in MIC can be attributed to the reduced degradation of $\beta$-lactam antibiotics because of a lack of $\beta$-lactamase activity or decreased permeability of $\beta$-lactam antibiotics due to the absence of porin.

$\mathrm{OmpC}$ and $\mathrm{OmpF}$ are considered as the leading transport porins that assist penetration of most $\beta$-lactam antibiotics [47,51-53], and both porins are known to be major protein components of $E$. coli OMVs [54]. Diffusion rates through these channels differ according to a substance's molecular weight and electrical charge $[48,55]$. Chemicals with hydrophilic molecules up to 600-700 Da in size can generally pass through the porin pores [56]. Among the six $\beta$-lactam antibiotics tested here (Figures 5 and 6), ampicillin with the lowest molecular weight (349 Da) and cefoperazone with the highest (645 Da) were able to penetrate the pores of the OMVs. Compounds with one negative charged group 
(monoanionic compounds) penetrate porin channels faster than zwitterionic compounds [55]. Of the antibiotics tested, cefotaxime, cefoperazone, and cefazolin are monoanionic compounds and ampicillin, amoxicillin, and cefalexin are zwitterionic compounds.

The OmpF porin allows more efficient permeation of solute molecules than the OmpC porin channel in terms of the size of the channel, in particular, OmpF channel is $7 \%$ to $9 \%$ larger than that of the OmpC channel [48]. The OmpC porin showed a notably lower influx of ampicillin and benzylpenicillin than $\mathrm{OmpF}$ in E. coli because of the greater number of charged residues in the OmpC channel than in that of OmpF [50], and the lack of OmpF undoubtedly affects the efficiency of $\beta$-lactam hyposensitivity compared with the loss of OmpC [51]. As shown in previous studies, the hydrolysis rate of $\Delta \mathrm{OmpF}$ OMVs was found to be lower than that of $\Delta \mathrm{OmpC}$ OMVs against $\beta$-lactam antibiotics (Figure 6). As a result, when respective OMVs were added to susceptible E. coli in the presence of antibiotics, the group treated with $\triangle \mathrm{OmpC}$ OMVs grew faster than the group treated with $\triangle \mathrm{OmpF}$ OMVs (Figure 5). Moya-Torres et al. (2014) demonstrated that the deletion of ompC or ompF showed almost the same production of $\beta$-lactamase compared with the wild-type [51]. The lack of OmpF or OmpC did not induce intrinsic $\beta$-lactamase activity by the OMVs (Figure 4), indicating that the reduced hydrolysis efficiency of $\beta$-lactam antibiotics by OMVs was a result of the decreased permeability of $\beta$-lactam antibiotics due to loss of the porins (Figures 5 and 6). Thus, our results indicate the crucial role of the porins in modulating the uptake of several $\beta$-lactam antibiotics into the lumen of OMVs, specifically, the influx of antibiotics is more efficient in the OmpF porin channel than the OmpC porin channel.

In summary, OMVs are important vehicles for substances related to $\beta$-lactam resistance, which help protect susceptible bacteria in the presence of $\beta$-lactam antibiotics. The mechanism of hydrolysis by OMVs against $\beta$-lactam antibiotics is not simply a one-protein effect, but rather an interaction between the $\beta$-lactamase in the lumen of OMVs and the porins on the surface of OMVs. The porin transports $\beta$-lactam antibiotics into the lumen of OMVs and $\beta$-lactamase in the lumen plays a key role in the direct degradation of the antibiotic. Our observation helps to elucidate the interaction of porins and $\beta$-lactamase in OMVs and increases our understanding of the resistance mechanisms found in multi-drug resistant bacteria.

\section{Materials and Methods}

\subsection{Bacterial Strains}

Antimicrobial-sensitive E. coli RC85 [7], antimicrobial-resistant E. coli RC85 ${ }^{+}$[7], and mutant $\mathrm{RC} 85^{+}$were used in this study. Bacteria were grown in Luria-Bertani (LB; Oxoid, Hampshire, UK) broth or LB agar. Broth cultures were grown at $37^{\circ} \mathrm{C}$ with orbital shaking. Growth was monitored by measuring absorbance at $600 \mathrm{~nm}\left(\mathrm{OD}_{600}\right)$ using an xMark microplate spectrophotometer (Bio-Rad, München, Germany).

\subsection{Molecular Cloning and Mutant Construction}

Plasmid pRed/ET (amp) was obtained from the "Quick \& Easy E. coli Gene deletion Kit" (Gene Bridges, Heidelberg, Germany) and the chloramphenicol resistance gene $\left(\mathrm{Cm}^{\mathrm{R}}\right)$ was amplified from pKINGeo/ccdB, which was designed in our laboratory [57]. An FRT-flanked, pro- and eukaryotic hygromycin selection cassette was obtained from "FRT-PGK-gb2-hygro-FRT template DNA" (Gene Bridges). The oligonucleotides (BIONEER, Daejeon, Korea) used in this study are listed in Table 2 and Table S1. The pRed/ET (amp) vector was modified by inserting the $\mathrm{Cm}^{\mathrm{R}}$ gene as a selection marker, because $\beta$-lactam-resistant E. coli $\mathrm{RC} 5^{+}$is resistant to ampicillin. Fragments 1 and 3 were amplified from pRed/ET (amp), while fragment 2 was amplified from pKINGeo/ccdB (Table S1). Another round of PCR was performed to combine fragments 2 and 3 using respective primers, and the resulting amplicons were used as a template for the last round of amplification to attach fragment 1 . The final DNA fragment flanked by Sac I and EcoRV was digested with Sac 
$\mathrm{I} / \mathrm{EcoRV}$ and ligated into the Sac I/Msc I sites of pRed/ET (amp), forming the pRed/ET $\left(\mathrm{Cm}^{\mathrm{R}}\right)$. The "Quick \& Easy E. coli Gene Deletion Kit" was used to construct the gene deletion mutant strains according to the manufacturer's protocol, with some modifications [58]. The pRed/ET $\left(\mathrm{Cm}^{\mathrm{R}}\right)$ expression plasmid was transformed into the E. coli strain $\mathrm{RC} 85^{+}$by electroporation (Bio-Rad MicroPulser) at $1800 \mathrm{~V}$ with a 4 ms pulse rate. Transformants $\left(\mathrm{RC} 85^{+}+\right.$pRedET) were selected on LB agar containing $35 \mu \mathrm{g} / \mathrm{mL}$ chloramphenicol (Sigma-Aldrich, USA) and grown overnight at $30^{\circ} \mathrm{C}$. A bacterial colony was selected from the plate and cultured in LB medium containing $35 \mu \mathrm{g} / \mathrm{mL}$ chloramphenicol overnight at $30^{\circ} \mathrm{C}$. Transformant cultures were re-incubated in super optimal broth (SOB) conditioned with L-arabinose (Sigma-Aldrich, St. Louis, MO, USA) at a final concentration of $0.3 \%(w / v)$ at $37^{\circ} \mathrm{C}$ until an $\mathrm{OD}_{600}$ of 0.2 was obtained to induce pRedET. Induced cells were harvested by centrifugation for $30 \mathrm{sec}$ at $16,000 \times g$ in a cooled microfuge benchtop centrifuge and re-suspended in chilled $10 \%(v / v)$ glycerol. This process was repeated five times before electroporation. Competent $\mathrm{RC} 85^{+}$cells were mixed with generated hygromycin cassettes flanked by homology arms to replace the DNA fragment (Table S1). Electroporation was performed with a Micropulser (Bio-Rad) delivering $1800 \mathrm{~V}$ for $4 \mathrm{~ms}$. Electroporated transformants were immediately removed from the cuvettes by mixing with $1 \mathrm{~mL}$ LB medium without antibiotics and incubated at $37^{\circ} \mathrm{C}$ for $3 \mathrm{~h}$ for recombination. Recombinant colonies were grown on LB agar containing $500 \mu \mathrm{g} / \mathrm{mL}$ hygromycin (Sigma-Aldrich) overnight at $37^{\circ} \mathrm{C}$ for selection. Gene deletion mutants were confirmed through colony PCR using the sequencing primers (Table 2). PCR products were visualized on a $1 \%$ agarose gel and the band size was confirmed by comparing with the non-mutant $E$. coli $\left(\mathrm{RC} 5^{+}\right)$. Colonies from gene deletion mutants were identified by matrix-assisted laser desorption ionization-time of flight mass spectrometry (MALDI-TOF MS; Bruker Daltonik, Bremen, Germany) [59] to confirm that they were indeed E. coli.

Table 2. Oligonucleotide sequence of primers and PCR product sizes.

\begin{tabular}{cccc}
\hline Primer & Oligonucleotide Sequence $\mathbf{( 5}^{\prime}$ to $\left.\mathbf{3}^{\prime}\right)$ & Target Gene & Fragment Size (bp) \\
\hline blc1-F & CTGGGTGTGGCATTGATTAAC & blc1 & 374 \\
blc1-R & TAACGTCGGCTCGGTACG & & \multirow{2}{*}{1103} \\
ompC-F & ATGAAAGTTAAAGTACTGTCCCTC & ompC & \multirow{2}{*}{599} \\
ompC-R & TTAGAACTGGTAAACCAGACCC & & ompF \\
ompF-F & CTGACCGGTTATGGTCAGTG & & \\
ompF-R & CGTTTTGTTGGCGAAGCC & & \\
\hline
\end{tabular}

\subsection{Analysis of Antibiotic Resistance}

Minimum inhibitory concentration (MIC) values were used to compare relative resistance levels of mutant strains to those of $\mathrm{RC} 85^{+}$. Eight $\beta$-lactam antibiotics, namely amoxicillin, ampicillin, cefalexin, cefazolin, cefoperazone, cefotaxime, cloxacillin, and methicillin (Sigma-Aldrich) and five other classes of antibiotics, including amikacin, colistin, kanamycin, nalidixic acid, and streptomycin (Sigma-Aldrich) were selected for this. The MIC of each antimicrobial agent was determined using the broth-dilution method in 96-well plates [60] according to Clinical and Laboratory Standards Institute (CLSI) guidelines, except that cation-adjusted Muller Hinton broth was substituted with LB. The listed MIC values were presented as the mean of three independent experiments.

\subsection{Isolation of Pure OMVs}

Purification of OMVs was performed as previously described [7]. Briefly, the bacteria culture was centrifuged at $6000 \times g$ for $20 \mathrm{~min}$, and the supernatant was filtered through $0.45-\mu \mathrm{m}$ pore-sized vacuum filters. The filtered supernatant was concentrated by ultrafiltration using a QuixStand Benchtop system (GE Healthcare, Uppsala, Sweden). This was then centrifuged at $150,000 \times g$ at $4{ }^{\circ} \mathrm{C}$ for $3 \mathrm{~h}$, and the OMVs purified on a continuous sucrose density gradient at $120,000 \times g$ at $4{ }^{\circ} \mathrm{C}$ for $18 \mathrm{~h}$. The OMV band was removed and centrifuged for $3 \mathrm{~h}$ at $150,000 \times \mathrm{g}$ at $4{ }^{\circ} \mathrm{C}$. The final OMV pellet was washed and resuspended in $10 \mathrm{mM}$ Tris- $\mathrm{HCl}(\mathrm{pH} 8.0)$ and filtered through a $0.2-\mu \mathrm{m}$ filter. All purification 
steps were performed at $4{ }^{\circ} \mathrm{C}$. The protein yields of OMV samples were measured using a Pierce BCA protein assay kit (Thermo Fisher Scientific, Foster City, CA, USA). Transmission electron microscopy (TEM) of OMVs was performed as previously described [7] using a Tecnai G2 Spirit Twin TEM system (FEI, Hillsboro, OR, USA). Dynamic light scattering (DLS) of OMVs for particle size distribution was performed as described previously [7] using a Nano ZS instrument (Malvern Instruments, Malvern, UK) and the Zetasizer software (version 7.11; Malvern Instruments).

\subsection{Effect of OMVs on the Growth of Bacteria in the Presence of $\beta$-Lactam Antibiotics}

The effect of OMVs on the growth of bacteria in the presence of $\beta$-lactam antibiotics was performed as previously described with slight modifications [7]. The effect of OMVs from $\mathrm{RC} 85^{+}, \Delta \mathrm{blc1} \mathrm{RC} 85^{+}$,

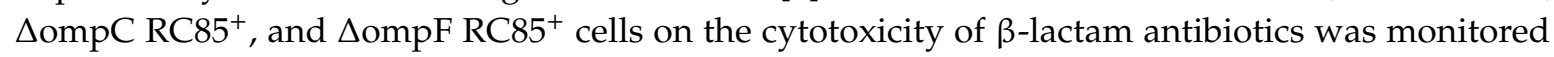
by assessing the growth of OMV-treated RC 85 cells. The $\beta$-lactam antibiotics used were: penicillin family (ampicillin and amoxicillin), first-generation cephalosporin (cefazolin and cefalexin), and the third-generation cephalosporin (cefotaxime and cefoperazone). The following six antibiotics were used at concentrations known to inhibit RC85 growth: ampicillin, $30 \mu \mathrm{g} / \mathrm{mL}$; cefotaxime, $1.25 \mu \mathrm{g} / \mathrm{mL}$; cefoperazone, $4 \mu \mathrm{g} / \mathrm{mL}$; amoxicillin, $12 \mu \mathrm{g} / \mathrm{mL}$; cefazolin, $8 \mu \mathrm{g} / \mathrm{mL}$; and cefalexin, $16 \mu \mathrm{g} / \mathrm{mL}$. The MIC of $\beta$-lactam antibiotics against the RC85 were listed in Table S2. Cultured RC 85 cells $\left(5 \times 10^{5} \mathrm{CFU} / \mathrm{mL}\right)$ were inoculated into medium containing one of these antibiotics and $5 \mu \mathrm{g} / \mathrm{mL}$ of the respective OMV sample. RC85 in the antibiotic-free medium was used as a positive control, while the negative control consisted of bacteria and growth-inhibitory concentrations of the respective antibiotics. All tubes were incubated at $37^{\circ} \mathrm{C}$ with shaking at $150 \mathrm{rpm}$. All experiments were performed in the dark to exclude the effect of light on the stability of the antibiotics used. The bacterial growth curves at $\mathrm{OD}_{600}$ were recorded at 3-h intervals up to $36 \mathrm{~h}$ using an xMark microplate spectrophotometer. Experiments were performed using three independent sets of bacterial cultures. The bacterial cultures were inoculated onto TSA with or without the respective same concentrations of antibiotics to confirm whether the susceptible bacteria could survive by antibiotic-resistant gene transfer via OMVs. Colonies from each cultured sample ( $n=5$, colonies per sample) on TSA without antibiotics were randomly selected and identified by MALDI Biotyper [59] to check contamination by other bacteria.

\subsection{Quantification of $\beta$-Lactamase Activity}

To test the differences in $\beta$-lactamase activity between OMVs from $\mathrm{RC} 85^{+}$and mutant strains, a colorimetric $\beta$-lactamase activity assay kit (BioVision, New Minas, NS, Canada) was used according to the manufacturer's instructions. The assay is based on the hydrolysis of nitrocefin, a chromogenic cephalosporin producing a colored product that can be measured spectrophotometrically $\left(\mathrm{OD}_{490}\right)$. A buffer of $10 \mathrm{mM}$ Tris- $\mathrm{HCl}$ ( $\mathrm{pH}$ 8.0) was used as a negative control and lyophilized positive control included in the kit was used. The quantity of enzyme capable of hydrolyzing $1.0 \mu \mathrm{M}$ of nitrocefin $/ \mathrm{min}$ at $25{ }^{\circ} \mathrm{C}$ corresponds to $1 \mathrm{U}$ of $\beta$-lactamase. To liberate $\beta$-lactamase from the lumen of OMVs, each obtained OMVs were sonicated from $5 \mathrm{~min}$ (the effective sonication time on release $\beta$-lactamase from E. coli) [61], cooled on ice for $5 \mathrm{~min}$ [62], and centrifuged at $16,000 \times g$ at $4{ }^{\circ} \mathrm{C}$ for $20 \mathrm{~min}$. Equal concentrations of each OMV sample $(2.5 \mu \mathrm{g})$ were dispensed into the wells of a clear flat-bottomed 96-well, and nitrocefin and buffer (provided in the kit) were added to make a final volume of $100 \mu \mathrm{L}$. The absorbance at $\mathrm{OD}_{490}$ was immediately measured in kinetic mode for $60 \mathrm{~min}$ at $25^{\circ} \mathrm{C}$. For all measurements, three independent experiments were performed. A standard curve was generated using $0,4,8,12,16$, and $20 \mathrm{nmol}$ of nitrocefin, and the specific $\beta$-lactamase activity of each sample was expressed in milliunits/milligram of protein.

\subsection{Measurement of Antibiotic Concentrations}

Measurement of $\beta$-lactam antibiotic concentrations was carried out as previously described [7], with slight modifications. The effect of OMVs from $\mathrm{RC} 85^{+}$and mutants on the degradation of the six antibiotics listed above in a cell-free system were analyzed by liquid chromatography/electrospray 
ionization mass spectrometry (LC-ESI-QQQ-MS/MS; 6420 Triple Quad LC/MS; Agilent, Waldbronn, Germany). A $5 \mu \mathrm{g} / \mathrm{mL}$ sample of respective OMV in PBS was mixed with ampicillin $(30 \mu \mathrm{g} / \mathrm{mL})$, cefotaxime $(1.25 \mu \mathrm{g} / \mathrm{mL})$, cefoperazone $(4 \mu \mathrm{g} / \mathrm{mL})$, amoxicillin $(12 \mu \mathrm{g} / \mathrm{mL})$, cefazolin $(8 \mu \mathrm{g} / \mathrm{mL})$, or cefalexin $(16 \mu \mathrm{g} / \mathrm{mL})$. Filtered PBS containing the respective antibiotics without OMVs was used as a positive control. All samples were incubated at $37^{\circ} \mathrm{C}$ with shaking at $150 \mathrm{rpm}$ and diluted 20 -fold prior to analysis. The concentrations of antibiotics were recorded at specific time points (ampicillin; $5 \mathrm{~h}$, cefotaxime; $4 \mathrm{~h}$, cefoperazone; $3 \mathrm{~h}$, amoxicillin; $5 \mathrm{~h}$, cefazolin; $1 \mathrm{~h}$, and cefalexin; $11 \mathrm{~h}$ ) in triplicate. For LC-MS/MS, LC-MS grade water (Burdick \& Jackson, Muskegon, MI, USA) containing $5 \mathrm{mM}$ ammonium formate (Sigma-Aldrich) and 0.1\% formic acid (KANTO, Tokyo, Japan) (v/v) (solution A) and LC grade methanol (Burdick \& Jackson) containing $5 \mathrm{mM}$ ammonium formate with $0.1 \%$ formic $\operatorname{acid}(\mathrm{v} / \mathrm{v})$ (solution B) were used as the mobile phase, at an initial A:B ratio of 30:70 or 50:50, depending on the antibiotic of interest. The compounds were separated using a Poroshell 120 EC-C18 column $(2.1 \times 100 \mathrm{~mm}, 2.7 \mu \mathrm{m}$; Agilent). Isocratic elution with phases A and B was followed by $3 \mathrm{~min}$ of total chromatography. The flow rate was $0.2 \mathrm{~mL} / \mathrm{min}$, the column temperature was $30{ }^{\circ} \mathrm{C}$, and $99.99 \%$ pure nitrogen gas was used for desolvation. For the quantification of antibiotics, at least two or more transitions were selected for each analyte and the positive electric spray ionization (ESI+) was used with the multiple reaction monitoring (MRM) mode. The MassHunter software (version B.06.00; Agilent) was used to process the LC-MS/MS data and quantification of the analytes.

\subsection{Statistical Analysis}

Statistical analysis was performed using Graphpad Prism, version 8.1.1. (GraphPad, CA, USA). Significant differences were determined by One-way Analysis of Variance (ANOVA). Data are presented as mean \pm standard deviation (SD). The difference was considered statistically significant at $p<0.05$.

\subsection{Data Availability}

All data generated or analyzed during this study are included in this published article and its Supplementary files.

Supplementary Materials: Supplementary materials can be found at http://www.mdpi.com/1422-0067/21/8/2822/s1.

Author Contributions: Conceptualization, S.W.K., J.S.L., C.-R.L., and T.S.J.; Data curation, S.W.K., J.S.L., S.B.P., A.R.L., J.W.J., J.H.C., J.M.S.L., J.K., and T.S.J.; Formal analysis, S.B.P., A.R.L., J.H.C., J.-S.S., J.-H.K., and J.-W.S.; Investigation, S.W.K., A.R.L., J.W.J., and J.K.; Supervision, T.S.J.; Validation, M.J., and T.S.J.; Visualization, M.W.H.; Writing—original draft, S.W.K., and J.M.S.L.; Writing—review \& editing, S.W.K., S.B.P., K.D.T., C.-R.L., and T.S.J. All authors have read and agreed to the published version of the manuscript.

Funding: This research was funded by Ministry of Food and Drug Safety in 2020, grant number 19162MFDS563.

Conflicts of Interest: The authors declare no conflict interest.

\section{References}

1. Nazir, T.; Abraham, S.; Islam, A. Emergence of potential superbug Mycobacterium tuberculosis, lessons from New Delhi mutant-1 bacterial strains. Int. J. Health Sci. 2012, 6, 87. [CrossRef]

2. Singh, S. Irrational use of antimicrobial agents. JDR Clin. Trans. Res. 2018, 2, 1-2. [CrossRef]

3. Antimicrobial Resistance: Tackling a Crisis for the Health and Wealth of Nations. Review on Antimicrobial Resistance: Chaired by Jim O'Neill. 2014. Available online: http://amr-review.org/Publications (accessed on 1 September 2015).

4. Centers for Disease Control and Prevention. Antibiotic resistance threats in the United States, 2013; Centres for Disease Control and Prevention: Atlanta, GA, USA, 2013.

5. Antimicrobial Resistance: Tackling Drug-Resistant Infections Globally: Final Report and Recommendations. Chaired by Jim O’Neill. 2016. Available online: http://amr-review.org/sites/default/files/160518_Final\% 20paper_with\%20cover.pdf (accessed on 27 March 2017).

6. Lammie, S.L.; Hughes, J.M. Antimicrobial resistance, food safety, and one health: The need for convergence. Annu. Rev. Food Sci. Technol. 2016, 7, 287-312. [CrossRef] [PubMed] 
7. Kim, S.W.; Park, S.B.; Im, S.P.; Lee, J.S.; Jung, J.W.; Gong, T.W.; Lazarte, J.M.S.; Kim, J.; Seo, J.-S.; Kim, J.-H. Outer membrane vesicles from $\beta$-lactam-resistant Escherichia coli enable the survival of $\beta$-lactam-susceptible E. coli in the presence of $\beta$-lactam antibiotics. Sci. Rep. 2018, 8, 5402. [CrossRef] [PubMed]

8. Beveridge, T.J. Structures of gram-negative cell walls and their derived membrane vesicles. J. Bacteriol. 1999, 181, 4725-4733. [CrossRef]

9. Kulkarni, H.M.; Nagaraj, R.; Jagannadham, M.V. Protective role of E. coli outer membrane vesicles against antibiotics. Microbiol. Res. 2015, 181, 1-7. [CrossRef]

10. Turner, K.L.; Cahill, B.K.; Dilello, S.K.; Gutel, D.; Brunson, D.N.; Albertí, S.; Ellis, T.N. Porin loss impacts the host inflammatory response to outer membrane vesicles of Klebsiella pneumoniae. Antimicrob. Agents Chemother. 2016, 60, 1360-1369. [CrossRef]

11. Schooling, S.R.; Beveridge, T.J. Membrane vesicles: An overlooked component of the matrices of biofilms. J. Bacteriol. 2006, 188, 5945-5957. [CrossRef]

12. Kulp, A.; Kuehn, M.J. Biological functions and biogenesis of secreted bacterial outer membrane vesicles. Annu. Rev. Microbiol. 2010, 64, 163-184. [CrossRef]

13. Yaron, S.; Kolling, G.L.; Simon, L.; Matthews, K.R. Vesicle-mediated transfer of virulence genes from Escherichia coli O157: H7 to other enteric bacteria. Appl. Environ. Microbiol. 2000, 66, 4414-4420. [CrossRef]

14. Kwon, S.-O.; Gho, Y.S.; Lee, J.C.; Kim, S.I. Proteome analysis of outer membrane vesicles from a clinical Acinetobacter baumannii isolate. FEMS Microbiol. Lett. 2009, 297, 150-156. [CrossRef] [PubMed]

15. Mashburn, L.M.; Whiteley, M. Membrane vesicles traffic signals and facilitate group activities in a prokaryote. Nature 2005, 437, 422. [CrossRef] [PubMed]

16. Schertzer, J.W.; Whiteley, M. Bacterial outer membrane vesicles in trafficking, communication and the host-pathogen interaction. J. Mol. Microbiol. Biotechnol. 2013, 23, 118-130. [CrossRef] [PubMed]

17. Deatherage, B.L.; Cookson, B.T. Membrane vesicle release in bacteria, eukaryotes, and archaea: A conserved yet underappreciated aspect of microbial life. Infect. Immun. 2012, 80, 1948-1957. [CrossRef]

18. Rumbo, C.; Fernández-Moreira, E.; Merino, M.; Poza, M.; Mendez, J.A.; Soares, N.C.; Mosquera, A.; Chaves, F.; Bou, G. Horizontal transfer of the OXA-24 carbapenemase gene via outer membrane vesicles: A new mechanism of dissemination of carbapenem resistance genes in Acinetobacter baumannii. Antimicrob. Agents Chemother. 2011, 55, 3084-3090. [CrossRef]

19. Lee, J.; Lee, E.-Y.; Kim, S.-H.; Kim, D.-K.; Park, K.-S.; Kim, K.P.; Kim, Y.-K.; Roh, T.-Y.; Gho, Y.S. Staphylococcus aureus extracellular vesicles carry biologically active $\beta$-lactamase. Antimicrob. Agents Chemother. 2013, 57, 2589-2595. [CrossRef]

20. Schaar, V.; Nordström, T.; Mörgelin, M.; Riesbeck, K. Moraxella catarrhalis outer membrane vesicles carry $\beta$-lactamase and promote survival of Streptococcus pneumoniae and Haemophilus influenzae by inactivating amoxicillin. Antimicrob. Agents Chemother. 2011, 55, 3845-3853. [CrossRef]

21. Kulkarni, H.M.; Swamy, C.V.; Jagannadham, M.V. Molecular characterization and functional analysis of outer membrane vesicles from the antarctic bacterium Pseudomonas syringae suggest a possible response to environmental conditions. J. Proteome Res. 2014, 13, 1345-1358. [CrossRef]

22. Doumith, M.; Ellington, M.J.; Livermore, D.M.; Woodford, N. Molecular mechanisms disrupting porin expression in ertapenem-resistant Klebsiella and Enterobacter spp. clinical isolates from the UK. J. Antimicrob. Chemother. 2009, 63, 659-667. [CrossRef]

23. Bavoil, P.; Nikaido, H.; von Meyenburg, K. Pleiotropic transport mutants of Escherichia coli lack porin, a major outer membrane protein. Mol. Gen. Genet. 1977, 158, 23-33. [CrossRef]

24. Nikaido, H.; Song, S.A.; Shaltiel, L.; Nurminen, M. Outer membrane of Salmonella XIV. Reduced transmembrane diffusion rates in porin-deficient mutants. Biochem. Biophys. Res. Commun. 1977, 76, 324-330. [CrossRef]

25. Pagès, J.-M.; James, C.E.; Winterhalter, M. The porin and the permeating antibiotic: A selective diffusion barrier in Gram-negative bacteria. Nat. Rev. Microbiol. 2008, 6, 893. [CrossRef] [PubMed]

26. Lamers, R.P.; Nguyen, U.T.; Nguyen, Y.; Buensuceso, R.N.; Burrows, L.L. Loss of membrane-bound lytic transglycosylases increases outer membrane permeability and $\beta$-lactam sensitivity in Pseudomonas aeruginosa. Microbiologyopen 2015, 4, 879-895. [CrossRef] [PubMed]

27. Schaar, V.; Paulsson, M.; Mörgelin, M.; Riesbeck, K. Outer membrane vesicles shield Moraxella catarrhalis $\beta$-lactamase from neutralization by serum IgG. J. Antimicrob. Chemother. 2012, 68, 593-600. [CrossRef] 
28. Fulsundar, S.; Harms, K.; Flaten, G.E.; Johnsen, P.J.; Chopade, B.A.; Nielsen, K.M. Gene transfer potential of outer membrane vesicles of Acinetobacter baylyi and effects of stress on vesiculation. Appl. Environ. Microbiol. 2014, 80, 3469-3483. [CrossRef]

29. Renelli, M.; Matias, V.; Lo, R.Y.; Beveridge, T.J. DNA-containing membrane vesicles of Pseudomonas aeruginosa PAO1 and their genetic transformation potential. Microbiology 2004, 150, 2161-2169. [CrossRef]

30. Schwechheimer, C.; Kuehn, M.J. Outer-membrane vesicles from Gram-negative bacteria: Biogenesis and functions. Nat. Rev. Microbiol. 2015, 13, 605. [CrossRef]

31. Manning, A.J.; Kuehn, M.J. Contribution of bacterial outer membrane vesicles to innate bacterial defense. BMC Microbiol. 2011, 11, 258. [CrossRef]

32. Andreoni, F.; Toyofuku, M.; Menzi, C.; Kalawong, R.; Shambat, S.M.; François, P.; Zinkernagel, A.S.; Eberl, L. Antibiotics stimulate formation of vesicles in Staphylococcus aureus in both phage-dependent and-independent fashions and via different routes. Antimicrob. Agents Chemother. 2019, 63, e01439-18. [CrossRef]

33. Quan, K.; Zhu, Z.; Cao, S.; Zhang, F.; Miao, C.; Wen, X.; Huang, X.; Wen, Y.; Wu, R.; Yan, Q. Escherichia coli-derived outer membrane vesicles deliver galactose-1-phosphate uridyltransferase and yield partial protection against Actinobacillus pleuropneumoniae in mice. J. Microbiol. Biotechnol. 2018, 28, 2095-2105. [CrossRef]

34. McBroom, A.J.; Johnson, A.P.; Vemulapalli, S.; Kuehn, M.J. Outer membrane vesicle production by Escherichia coli is independent of membrane instability. J. Bacteriol. 2006, 188, 5385-5392. [CrossRef] [PubMed]

35. Schwechheimer, C.; Kulp, A.; Kuehn, M.J. Modulation of bacterial outer membrane vesicle production by envelope structure and content. BMC Microbiol. 2014, 14, 324. [CrossRef] [PubMed]

36. Valeru, S.P.; Shanan, S.; Alossimi, H.; Saeed, A.; Sandström, G.; Abd, H. Lack of outer membrane protein A enhances the release of outer membrane vesicles and survival of Vibrio cholerae and suppresses viability of Acanthamoeba castellanii. Int. J. Microbiol. 2014, 2014, 610190. [CrossRef] [PubMed]

37. Nogami, T.; Mizushima, S. Outer membrane porins are important in maintenance of the surface structure of Escherichia coli cells. J. Bacteriol. 1983, 156, 402-408. [CrossRef] [PubMed]

38. Holten, K.B. Appropriate prescribing of oral beta-lactam antibiotics. Am. Fam. Physician 2000, 62, 611-620. [PubMed]

39. Jaffe, A.; Chabbert, Y.A.; Semonin, O. Role of porin proteins OmpF and OmpC in the permeation of beta-lactams. Antimicrob. Agents Chemother. 1982, 22, 942-948. [CrossRef]

40. Drawz, S.M.; Bonomo, R.A. Three decades of $\beta$-lactamase inhibitors. Clin. Microbiol. Rev. 2010, 23, $160-201$. [CrossRef]

41. Davies, J. Inactivation of antibiotics and the dissemination of resistance genes. Science 1994, 264, 375-382. [CrossRef]

42. Nikaido, H.; Nakae, T. The outer membrane of Gram-negative bacteria. In Advances in Microbial Physiology; Elsevier: Amsterdam, The Netherlands, 1980; Volume 20, pp. 163-250.

43. Nakae, T. Outer membrane of Salmonella. Isolation of protein complex that produces transmembrane channels. J. Biol. Chem. 1976, 251, 2176-2178.

44. Nikaido, H. Molecular basis of bacterial outer membrane permeability revisited. Microbiol. Mol. Biol. Rev. 2003, 67, 593-656. [CrossRef]

45. Wang, X.; Minasov, G.; Shoichet, B.K. Evolution of an antibiotic resistance enzyme constrained by stability and activity trade-offs. J. Mol. Biol. 2002, 320, 85-95. [CrossRef]

46. Hwang, J.; Cho, K.-H.; Song, H.; Yi, H.; Kim, H.S. Deletion mutations conferring substrate spectrum extension in the class A $\beta$-lactamase. Antimicrob. Agents Chemother. 2014, 58, 6265-6269. [CrossRef] [PubMed]

47. Choi, U.; Lee, C.-R. Distinct roles of outer membrane porins in antibiotic resistance and membrane integrity in Escherichia coli. Front. Microbiol. 2019, 10, 953. [CrossRef] [PubMed]

48. Nikaido, H.; Rosenberg, E.; Foulds, J. Porin channels in Escherichia coli: Studies with beta-lactams in intact cells. J. Bacteriol. 1983, 153, 232-240. [CrossRef]

49. Lou, H.; Chen, M.; Black, S.S.; Bushell, S.R.; Ceccarelli, M.; Mach, T.; Beis, K.; Low, A.S.; Bamford, V.A.; Booth, I.R. Altered antibiotic transport in OmpC mutants isolated from a series of clinical strains of multi-drug resistant E. coli. PLoS ONE 2011, 6, e25825. [CrossRef]

50. Kojima, S.; Nikaido, H. High salt concentrations increase permeability through OmpC channels of Escherichia coli. J. Biol. Chem. 2014, 289, 26464-26473. [CrossRef] 
51. Moya-Torres, A.; Mulvey, M.R.; Kumar, A.; Oresnik, I.J.; Brassinga, A.K.C. The lack of OmpF, but not OmpC, contributes to increased antibiotic resistance in Serratia marcescens. Microbiology 2014, 160, 1882-1892. [CrossRef]

52. Dutzler, R.; Rummel, G.; Albertí, S.; Hernández-Allés, S.; Phale, P.; Rosenbusch, J.; Benedi, V.; Schirmer, T. Crystal structure and functional characterization of OmpK36, the osmoporin of Klebsiella pneumoniae. Structure 1999, 7, 425-434. [CrossRef]

53. Delcour, A.H. Outer membrane permeability and antibiotic resistance. Biochim Biophys Acta Proteins Proteom 2009, 1794, 808-816. [CrossRef]

54. Lee, E.Y.; Bang, J.Y.; Park, G.W.; Choi, D.S.; Kang, J.S.; Kim, H.J.; Park, K.S.; Lee, J.O.; Kim, Y.K.; Kwon, K.H. Global proteomic profiling of native outer membrane vesicles derived from Escherichia coli. Proteomics 2007, 7, 3143-3153. [CrossRef]

55. Yoshimura, F.; Nikaido, H. Diffusion of beta-lactam antibiotics through the porin channels of Escherichia coli K-12. Antimicrob. Agents Chemother. 1985, 27, 84-92. [CrossRef] [PubMed]

56. Franklin, T.J.; Snow, G.A. Biochemistry and Molecular Biology of Antimicrobial Drug Action; Springer Science \& Business Media: Berlin/Heidelberg, Germany, 2005.

57. Kim, J.; Im, S.P.; Lee, J.S.; Lazarte, J.M.S.; Kim, S.W.; Jung, J.W.; Kim, J.Y.; Kim, Y.R.; Lee, S.; Kim, G.J. Globular-shaped variable lymphocyte receptors B antibody multimerized by a hydrophobic clustering in hagfish. Sci. Rep. 2018, 8, 10801. [CrossRef] [PubMed]

58. Heermann, R.; Zeppenfeld, T.; Jung, K. Simple generation of site-directed point mutations in the Escherichia coli chromosome using $\operatorname{Red}^{\circledR} / \mathrm{ET}^{\circledR}$ Recombination. Microb. Cell Fact. 2008, 7, 14. [CrossRef] [PubMed]

59. Kim, S.W.; Jang, H.B.; Lee, J.S.; Im, S.P.; Lazarte, J.M.S.; Seo, J.P.; Lee, W.J.; Kim, J.S.; Jung, T.S. Comparison of proteome typing and serotyping of Streptococcus parauberis isolates from olive flounder (Paralichthys olivaceus). J. Microbiol. Methods 2015, 118, 168-172. [CrossRef]

60. Andrews, J.M. Determination of minimum inhibitory concentrations. J. Antimicrob. Chemother. 2001, 48 (Suppl. 1), 5-16. [CrossRef] [PubMed]

61. Shokri, A.; Larsson, G. Characterisation of the Escherichia coli membrane structure and function during fedbatch cultivation. Microb. Cell Fact. 2004, 3, 9. [CrossRef]

62. Bush, K.; Singer, S.B. Effective cooling allows sonication to be used for liberation of $\beta$-lactamases from Gramnegative bacteria. J. Antimicrob. Chemother. 1989, 24, 82-84. [CrossRef] 